\title{
AC Interference on Gas Pipelines due to Phase to Ground Faults in Overhead Transmission Lines
}

\author{
Ali I. El Gayar, Zulkurnain Abdul-Malek \\ Institute of High Voltage \& Current, Faculty of Electrical Engineering, Universiti Teknologi Malaysia, Johor, Malaysia
}

\section{Article Info}

Article history:

Received Feb 25, 2016

Revised Apr 3, 2016

Accepted Apr 15, 2016

\section{Keyword:}

CDEGS

Fault current

Gas pipeline

Induced voltage

Overhead transmission line

Right of way

\begin{abstract}
The purpose of this research is to investigate the severity of voltages induced on gas pipeline (GPL) installed in parallel to a $115-\mathrm{kV}$ overhead transmission line. The overhead transmission line (OHTL) is configured as a single-circuit with a single phase to ground fault occurred on one phase. Transmission of high voltage along the same right of way (ROW) with a metallic conductor may possibly introduce interference on the metallic conductor such as GPL due to power frequency voltage as well as due to phase faults and switching phenomena. Two main approaches were used to compute the induced voltages, namely the method of moment (MOM), which is based on the electromagnetic field theory, and the circuit based method. The simulation considers a $30-\mathrm{km}$-long OHTL and a 10-km-long GPL. The GPL is buried at 1 -m depth in a homogenous earth structure with varying soil resistivites from 10 to $1000-\mathrm{m}$. The transmission line consists of 150 towers and 200-m span length. The separation distance between the GPL and OHTL is varied from 5 to $100 \mathrm{~m}$. The phase to ground fault current was varied from 0.5 to 10 kA. Several observation points were made throughout the corridor to examine the induced voltages at different locations. The results show that, the soil resistivity, separation distance, and fault current had significant effects on the GPL induced voltage. In the case of the observation points lying on the soil or on the outer surface of the GPL coating, the induced voltage increases, when the soil resistivity increases, as expected. In contrast, for the observation points placed inside the GPL metal, and the GPL is well coated, the induced voltage decreases when the soil resistivity increases.
\end{abstract}

Copyright (c) 2016 Institute of Advanced Engineering and Science. All rights reserved.

\section{Corresponding Author:}

Zulkurnain Abdul-Malek, Institute of High Voltage \& Current, Faculty of Electrical Engineering, Universiti Teknologi Malaysia, 81310 UTM Johor Bahru, Malaysia, $($ Fax $)+(6) 07-5578150$, Tel +(60)07-5535860.

Email: zulkurnain@utm.my

\section{INTRODUCTION}

Suitable earthing designs are also vital to ensure safe level of potential rise in the event of lightning strikes on various systems such as transmission lines [1]-[5]. The transient currents caused by faults and lightning strikes are dispersed into the earth through the grounding electrodes embedded inside the soil. The performance of grounding electrodes is dependent on the soil electrical properties, electrode dimensions, and current parameters. As a result, the transient resistance and capacitance of the electrode are also affected. It is also noted that the effect of soil dispersive behavior affects the soil ionization phenomenon, which occurs in high frequency lightning current discharges [6]-[11]. Recent work on the effects of soil electrical properties on the induced voltage in buried GPLs because of lightning current discharges in nearby overhead transmission lines (OHTLs) is described in [2].

The presence of GPLs in the vicinity of OHTLs is a serious concern to utilities due to interferences related to the OHTLs. Electric power transmitted at higher transmission voltages could possibly result in 
generation of higher electric fields. The fields created by the transmission of power give rise to a stiff competition for land as well as right of ways (ROWs) [12]. The strips of land vital to the OHTL also consist other industrial installations such as gas pipelines, railways, and highways. The proximity of OHTLs to metallic conductors poses threats such as those related to the issues of AC interference by the OHTL and corrosion of the metallic conductors. Gas pipelines located in the vicinity of the OHTLs are susceptible to the electric fields generated by power lines. The GPLs may absorb a portion of the generated energy during power system overload, switching operation, and faults [13]. Consequently, high currents and high voltages may be produced along the gas GPLs resulting from energy flowing from the power installation to the gas installation via common conductive path shared by both installations [14]. The induced voltages may cause personal and livestock injuries when in contact (by touching) with the GPL. In addition, GPL corrosions or damages on the GPL cathodic protection may also occur [13],[15]-[17]. The studies on the induced voltages on the gas GPLs because of interactions with nearby AC power transmission lines were carried out by many researchers [7]-[12]. In addition, other researchers investigated the effect of imperfect GPL coating and multilayer soil on the induced voltages [18],[19]. However, most of the works are focused on separately treated inductive and conductive couplings, and not so much on the total AC interference.

In this work, the AC total interference on the GPLs is studied by modeling different observation points and profiles along the pipe to examine the severity of the induced voltage. The induced voltage was divided into five types depending on the location of the observation points. The first type is the earth surface ground potential rise (GPR), which is the ground potential on the earth surface above the GPL. Secondly, the metal GPR, which is the potential rise on the metallic part (under the coating) of the GPL. The third type is the touch voltage, which can be obtained by vector substraction of the earth surface GPR from the metal GPR. The fourth type is called the coating GPR, which represents the potential rise on the outer surface of the GPL (above the coating). The coating stress voltage, which is the fifth type of the induced voltage, can be obtained by vector subtraction of the GPL coating GPR from the metal GPR. All these potential examined to illustrate the effect of induced voltages on GPLs due to phase to ground faults. Two approaches were used to conduct this study, namely, the electromagnetic field method, which is based on the method of moment (MOM) theory, and the approximation method, which utilised the ROW software.

\section{MODELS DESCRIPTION}

A specific configuration as shown in Figure 1 was chosen for this study. The model consists of a $115-\mathrm{kV}$ overhead transmission line and an underground GPL. The length of the OHTL is $30 \mathrm{~km}$. It has a single shield wire and 150 towers with $200-\mathrm{m}$ span length. Two substations feed the line with 830 -A current at steady state condition.

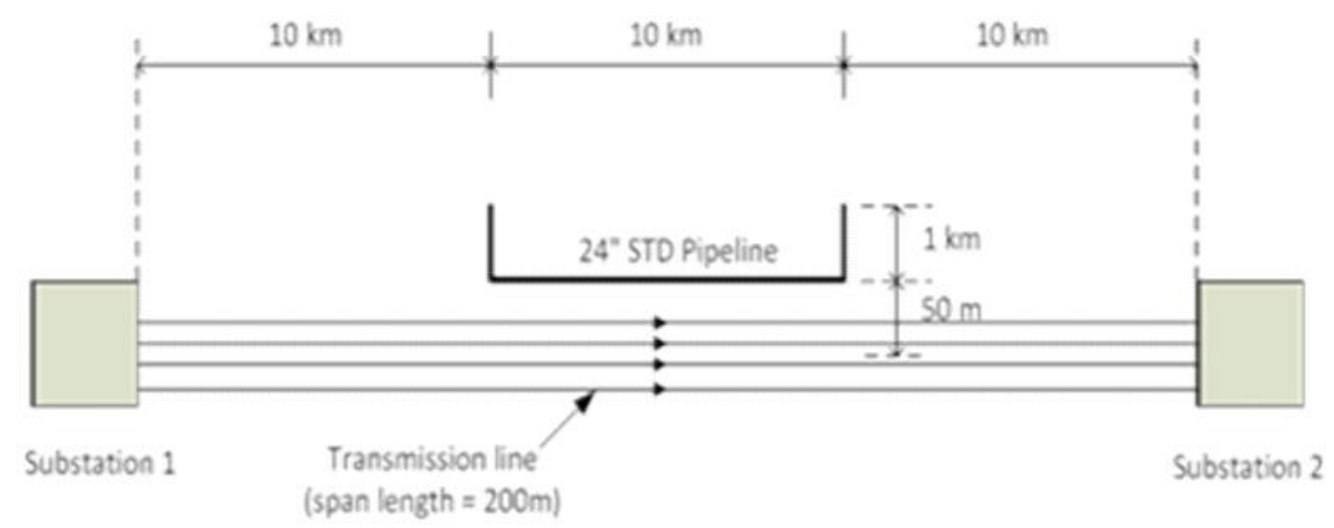

Figure 1. Top view of the modeled OHTL and GPL system showing the relevant cross section of the common corridor

\subsection{GPL Model}

The GPL is located at the center of the right-of-way and is $50 \mathrm{~m}$ away from the center of the power line. The GPL changes its direction perpendicularly at each end and continues for $1000 \mathrm{~m}$ before being terminated. The GPL was modeled with the dimensions and electrical characteristics shown in Table 1. 
Table 1. GPL dimensions and electrical characteristics

\begin{tabular}{ll}
\hline Pipeline Diameter & $0.610 \mathrm{~m}(24 \mathrm{in})$ \\
Wall thickness & $0.9527 \mathrm{~cm}(0.375 \mathrm{in})$ \\
Burial depth (cover) & $1 \mathrm{~m}(39.4 \mathrm{in})$ \\
Steel resistivity in p.u. (with respect to anneal copper) & 10 \\
Steel permeability (with respect to free space) & 300 \\
Ideal Coating resistance & $40,898,000 \mathrm{ohm}-\mathrm{m}$ \\
Coating thickness & $1 \mathrm{~mm}$ \\
Pipe type & $24 " \mathrm{STD}$ \\
Cross section & $576000 \mathrm{kcmil}$ \\
Conductor inner radius & $29.5275 \mathrm{~cm}$ \\
Pipeline share corridor & $10 \mathrm{~km}$ \\
\hline
\end{tabular}

\subsection{Transmission Line Model}

The average span length of the OHTL is $200 \mathrm{~m}$. The 477 ACSS type conductors with a radius of $1.074 \mathrm{~cm}$ were used. The permeability and resistivity of the conductor were set at $1 \mathrm{p} . \mathrm{u}$ and $1.6 \mathrm{p} . \mathrm{u}$, respectively. The location of the phase conductors are $24 \mathrm{~m}, 22.5 \mathrm{~m}$ and $21 \mathrm{~m}$ above the ground as shown in Figure 2. The shield wire has inner and outer radii of $0.255 \mathrm{~cm}$ and $0.771 \mathrm{~cm}$, respectively. It was located at $27 \mathrm{~m}$ above the ground. The OHTL tower grounding is accomplished using a $6.1-\mathrm{m}$ single grounding rod with $0.305-\mathrm{m}$-diameter. The tower footing grounding resistance was calculated based on the corresponding soil resistivity value. For the default soil resistivity of $100 \mathrm{ohm}-\mathrm{m}$, the tower grounding resistance is 10.7 $\mathrm{ohm}$. This is much higher than the corresponding substation grounding resistance of $0.5 \mathrm{ohm}$.

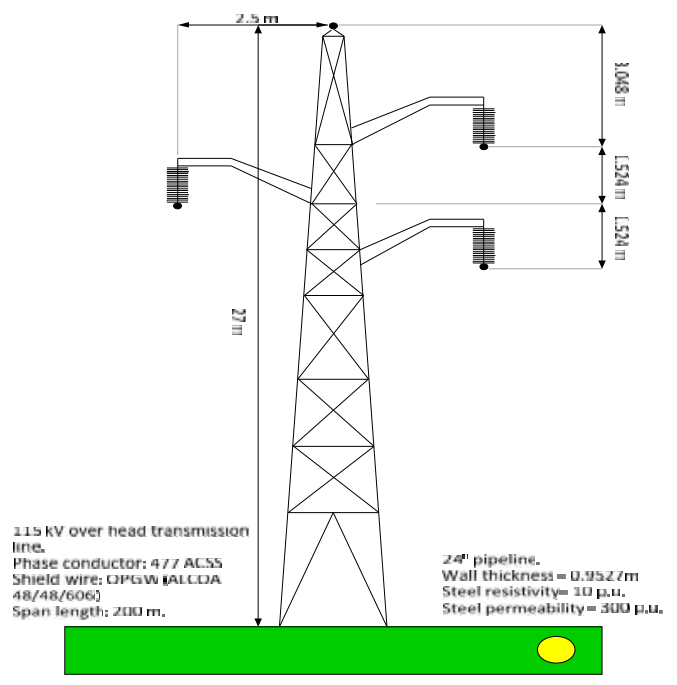

Figure 2. Cross-section of 115-kV OHTL tower

\subsection{Faults and Normal Current}

Under normal operation, two substations at the end terminals feed the OHTL with 830-A current. A single phase to ground fault was assumed to occur inside the right-of-way and at a point $15 \mathrm{~km}$ away from both terminals that is exactly in the middle of the corridor. By this assumption, the effects of both inductive and conductive interferences were considered. A 5000-A current was drawn from each end terminal towards the fault location. Table 3 illustrates the magnitude and phase angle of each fault current and its location.

Table 3. Fault current location and amount of current drawn from each end terminal

\begin{tabular}{ccc}
\hline Fault Location & From substation no.1 (A) & From substation No.2 (A) \\
\hline Substation No.1 & $5000-86.06^{\circ}$ & $5000 \_-86.06^{\circ}$ \\
Midway & $5000-86.06^{\circ}$ & $5000-86.06^{\circ}$ \\
Substation No.2 & $5000-86.06^{\circ}$ & $5000 \_-86.06^{\circ}$ \\
\hline
\end{tabular}

\subsection{Circuit Based Model}

To model the entire right of way network, the components of the OHTL and GPL were converted to the circuit based equivalents. Two terminals, namely 1 and 2, shown in Figure 3 represent the feeding 
substations. The central site is selected just outside of terminal 1. The two terminals supply currents to the lines. A total of 5 phases, and hence 5 busses, were used. Busses 1, 2, 3, 4 and 5 are the shield wire, phase A, phase B, phase C, and the 24-inch GPL under examination, respectively. The GPL starts from the 10-km point and stretches to the 20-km point of the corridor as shown in Figure 3, defined as region 2. No GPL exists beyond these two points. The regions where no parallel GPL exists are defined as regions 1 and 3 . Each region is divided into 50 separate sections for more accurate results. The shunt impedance of the overhead ground wire of each section are the tower ground resistances of the OHTL.

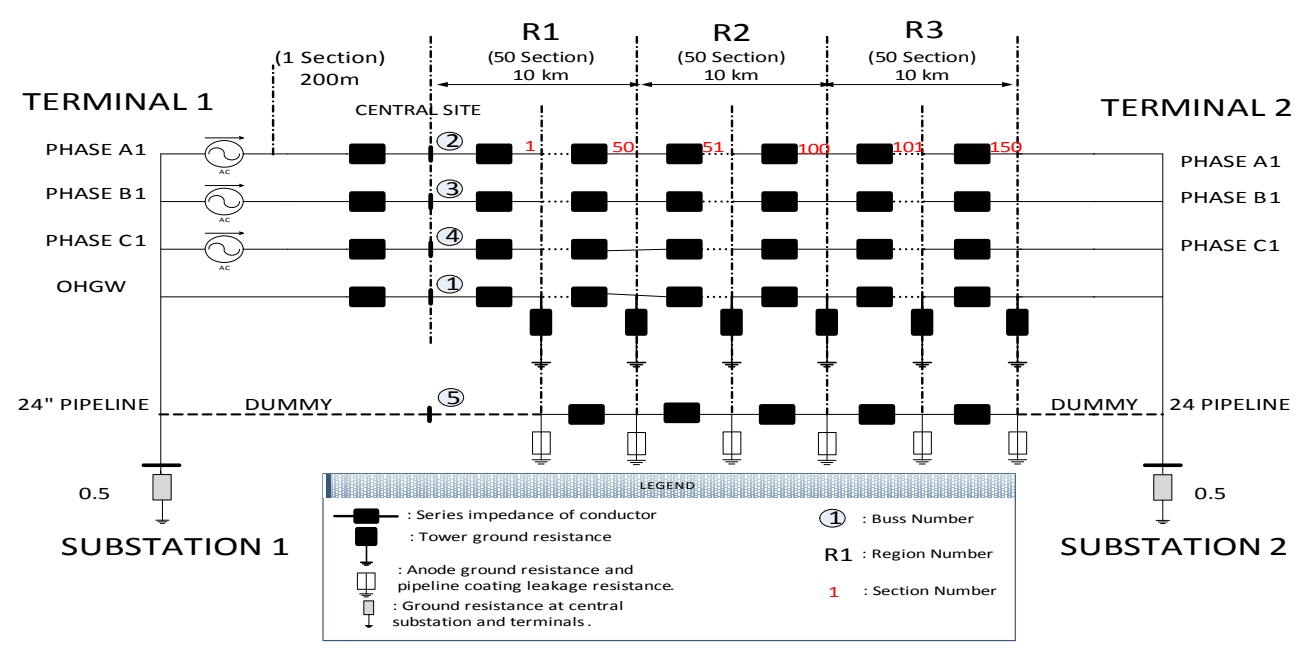

Figure 3. Circuit based model for the entire OHTL right-of-way

\section{RESULTS AND DISCUSSIONS}

To demonstrate the effect of induced voltage on the GPL, the induced voltages throughout the GPL was presented. The locations along the GPL where the maximum voltage occurs during the fault were determined. Thereafter, the maximum voltages at these locations were determined from different observation points along the GPL cross-section.

\subsection{Induced Voltage Along the GPL}

A uniform soil resistivity of $100-m$ was used when computing the metal and earth surface GPRs along the GPL. Figure 4 illustrates the earth surface GPR (about $1 \mathrm{~m}$ above the GPL centre) along the GPL with 1000 observation points. The profile is from one end of the GPL to the other end with a profile length of 10,000 meters.

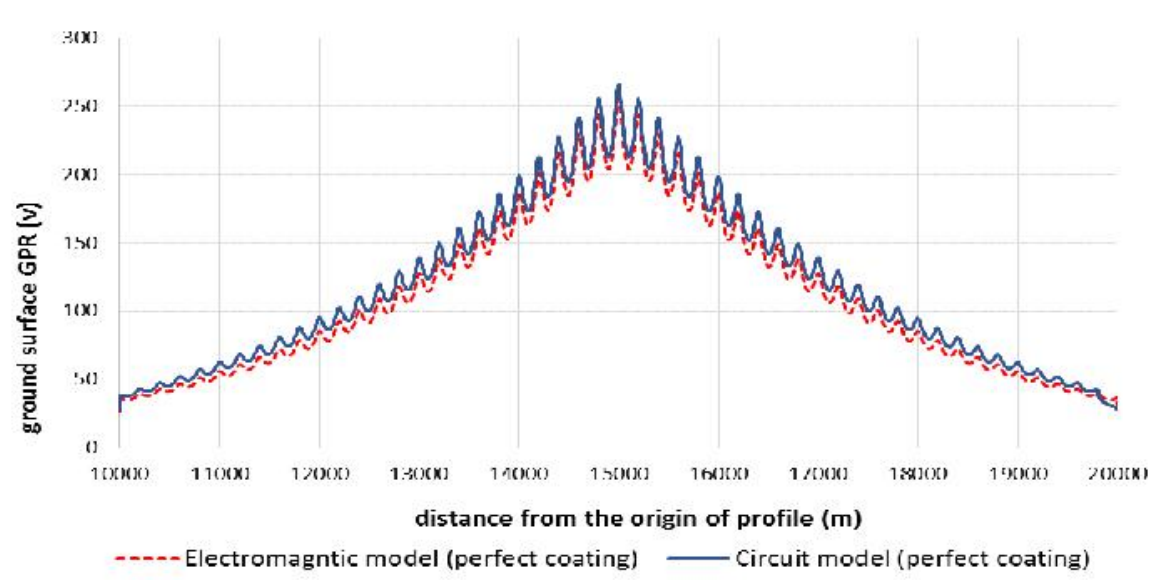

Figure 4. GPR on the soil surface along the GPL corridor, during fault at the middle of OHTL 
In view of the fault location in the middle of the OHTL ROW, the curves are symmetrical due to the symmetry of the system, as expected. The maximum ground potential occurs at midway along the corridor because of the high current injected to the soil during the fault condition and hence raises the soil potential in the vicinity. Figure 4 clearly shows the surface GPR decreases when moving away from the fault location. Generally, the electromagnetic and circuit based approaches give almost the same pattern of results. It is noted that the circuit based approach has upto 3.8\% difference when compared to the electromagnetic approach. This is because the circuit approach assumes an infinite length of OHTL when computing the line parameters.

Figure 5 shows the potential of the GPL metal (Metal GPR) along the GPL for the same fault condition. The potential rise of the GPL metal was determined by the cumulative EMF induced in the GPL by the current flowing in the overhead transmission line conductors. The pattern shows two minimum points and a pronounced peak at the fault location. The other peaks occur at the locations where the GPL ends or deviates away from the transmission line.

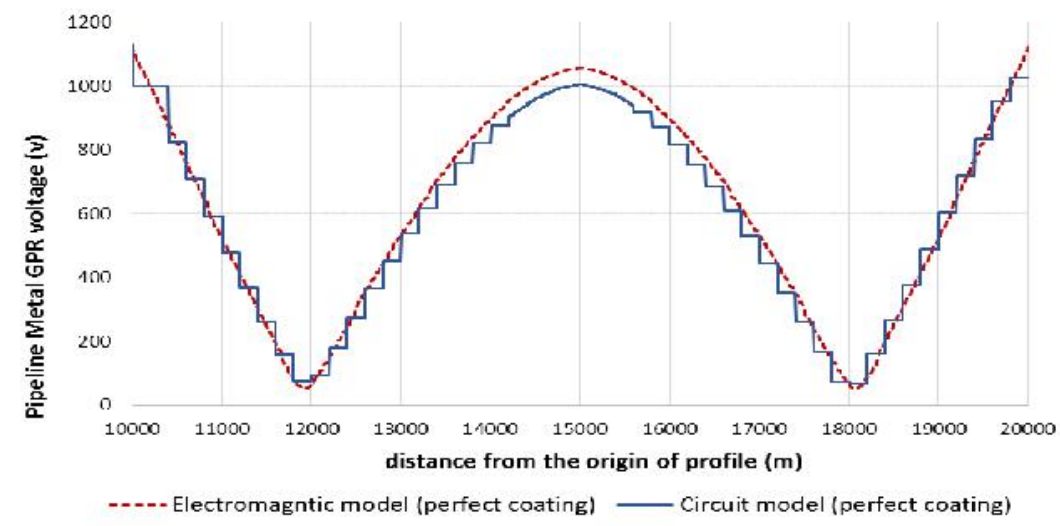

Figure 5. Metal GPR throughout GPL during fault at the middle of the OHTL

\subsection{Effects of Induced Voltage on GPL with respect to Variation of Distance of GPL from the Faulted Tower}

The same fault current of $5 \mathrm{kA}$ was drawn from each terminal of OHTL. The separation (between two parallel lines) distances between the pipe line and the faulted tower was altered at distances of 5, 10, 20, $30,40,50,60,80$, and $100 \mathrm{~m}$. The GPL was buried at $1 \mathrm{~m}$ underground. The voltages induced on the GPL at different observation points are depicted in Figure 6. It is seen from the curves that the induced voltages decrease when the GPL was taken further away from the OHTL. The GPL coating stress and the touch voltages had the highest induced voltages on the GPL compared to the metal, earth surface, and the outer coating surface GPR. This could damage the coating and accelerate the corrosion in the GPL metal.

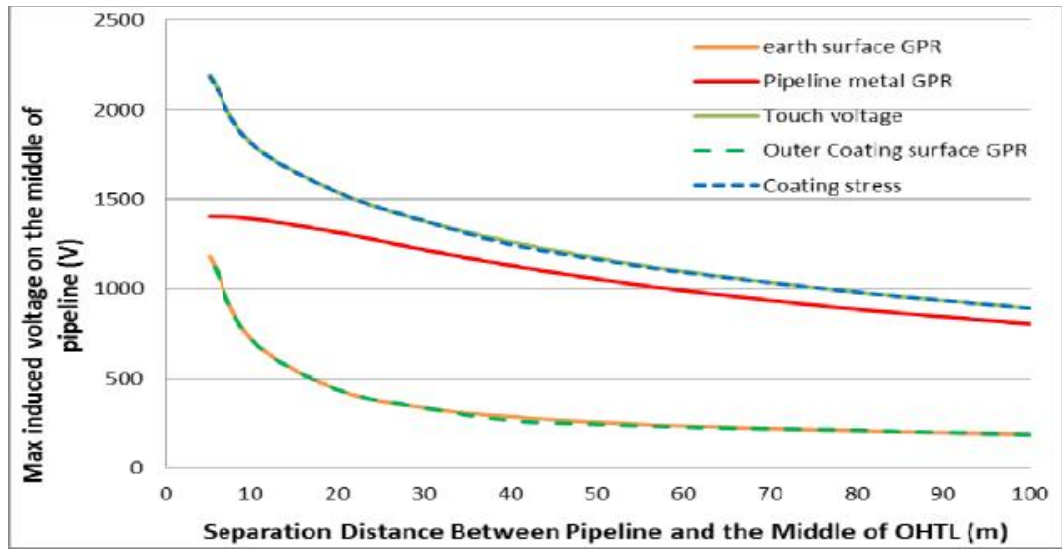

Figure 6. The effect of (parallel) separation distance between GPL and OHTL under fault condition 


\subsection{Effects of Soil Resistivity on Induced Voltages}

The effect of soil resistivity due to the interaction of steady-state electromagnetic fields and GPLs is known, that is, an increase in the soil resistivity will result in an increase in the induced voltage. In this work, the effect of soil resistivity on induced voltage on GPLs because of fault currents has been illustrated in Figure 7. The separation distance between the GPL and OHTL was kept constant at $50 \mathrm{~m}$. In this figure, not only the effect of inductive interference was determined, but the effect of conductive interference was also taken in consideration, to represent the AC total interference.

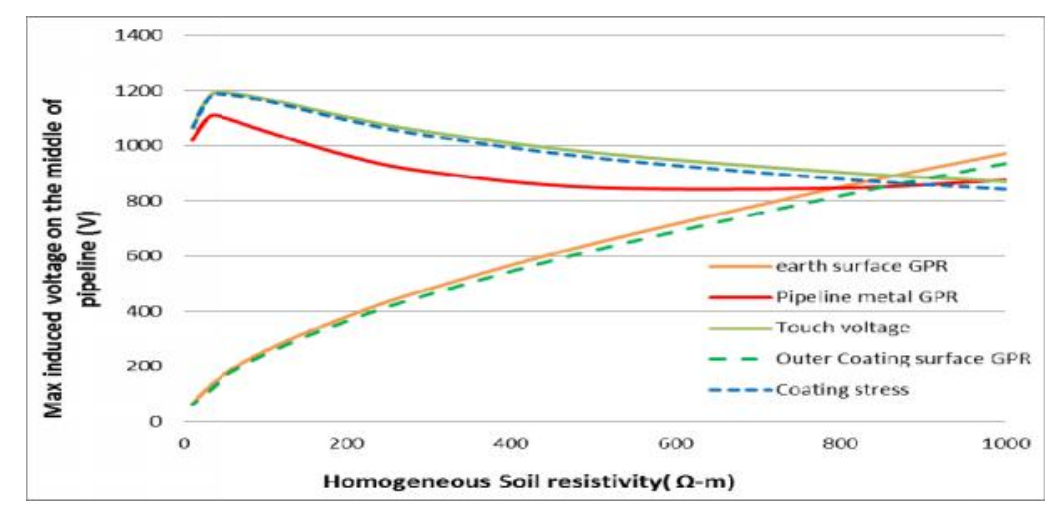

Figure 7. Variation in the induced voltage on GPL with respect to modification of soil resistivity, under local fault condition

As illustrated in Figure 7, the earth surfaces GPR and the outer coating surface GPR increase when the soil resistivity increases. This is because they directly depend on the conductive coupling, which in turn is dependent on the current injected to the ground through the tower grounding grid during fault condition. On the other hand, the metal GPR decreases when the soil resistivity increases. When the GPL is well coated, as the case in this study, the metal GPR is dependent only on the inductive interference. When the soil resistivity increases, the tower grounding resistance increases as well, thus making the shield wire attractiveness as a fault current return path to increase. This results in a greater proportion of the fault current to flow back towards the sources in the shield wires, and out of phase with the current in the faulted phase, thus reducing, by cancellation effect, the net emf induced in the GPL, and hence the cumulative GPR in the GPL. For the same reason that was mentioned above, the touch voltage and coating stress decrease when the soil resistivity increases, because they are dependent on the metal GPR.

\subsection{Effects of Induced Voltage on GPL due to Variation of Fault Current}

An increase in the fault current results in a corresponding increase in the induced voltage on the GPL, as shown in Figure 8. The GPL was $50 \mathrm{~m}$ away from the transmission path that was subjected to a single phase to ground fault. The metal GPR, coating stress, and touch voltage show higher values when compared to earth surface GPR and outer coating surface GPR. This is because the mutual impedance between the GPL and the phase conductor of OHTL is increased when the fault current increases. This causes the metal GPR to rapidly build up along the length of the GPL.

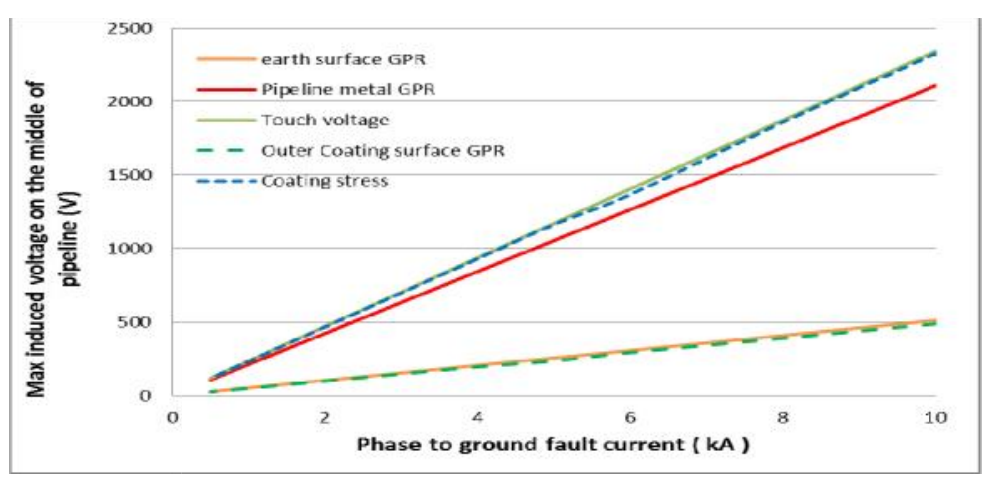




\section{CONCLUSION}

Figure 8. The variation of the induced voltage on the GPL with the peak fault current

The GPL induced voltages as a result of phase to ground faults had been computed using two software approaches. These are the method of moment (MOM), which is based on electromagnetic field theory, and the circuit based method. The circuit based method consists of the circuit grounding analysis to compute the conductive interference, and the circuit based models to compute the inductive interference. Different model parameters were varied to determine the extent of variation in the induced voltages on the GPL. Results show that the results using the electromagnetic approach are higher than those using the circuit based approach. This is mainly because of OHTL infinite length and uniformly parallel assumptions made in the circuit based method. It can be concluded that electromagnetic approach gives more accurate results due to its more accurate simulation models.

Studies on the effects of various model parameters show a more or less linear increment of induced voltage with the log of fault current and a linear decrease with OHTL-GPL separation. In addition the earth surface and outer surface coating GPRs also linearly increase with the log of soil resistivity. In contrast, a slightly linear decrease was observed for the metal GPR, the touch voltage, and the coating stress with the log of soil resistivity. The higher soil resistivity causes the tower ground resistance to increase, thus making the shield wire's attractiveness as a fault current return path to increase, which forces the induced net EMF and the cumulative GPR in the GPL to reduce.

The maximum ground potential occurs at midway along the corridor due to the high current injected ity. The surface GPR decreases when moving away from fault location when the GPL coating is ideal. The GPL metal potential remains relatively unaffected by the potential of the surrounding soil if the GPL coating is perfect.

\section{ACKNOWLEDGEMENTS}

In preparing this paper, the first author was in contact with many people, academicians, researchers and practitioners who contributed immensely towards his understanding and thoughts. The authors are also indebted to the Institute of High Voltage and High Current (IVAT) for providing the full version of CDEGS software with technical support. The author thanks Universiti Teknologi Malaysia for financially supporting this work through the research grant vote number 106H1.

\section{REFERENCES}

[1] D. Caulker, et al., "Evaluation of Lightning Performance of Overhead Transmission Line Based on $132 \mathrm{kV}$ Double Circuit Tower Structures," International Review on Modelling and Simulations, vol/issue: 3(6), 2010.

[2] A. I. Elgayar and Z. Abdul-Malek, "Induced Voltages on a Gas Pipeline due to Lightning Strikes on Nearby Overhead Transmission Line," International Journal of Electrical and Computer Engineering (IJECE), vol/issue: 6(2), 2016.

[3] D. Caulker, et al., "Shielding failure analysis of $132 \mathrm{kV}$ transmission line shielded by surge arresters associated with multiple strokes lightning," in Electrical and Computer Engineering (ICECE), 2010 International Conference on, 2010

[4] D. Caulker, et al., "Lightning Interaction with $132 \mathrm{kV}$ Transmission Line Protected by Surge Arresters," in Universities' Power Engineering Conference (UPEC), Proceedings of 2011 46th International, 2011.

[5] A. I. Elgayar, et al., "Wind-Induced Clearances Infringement of Overhead Power Lines," International Journal of Computer and Electrical Engineering, vol/issue: 6(4), pp. 275, 2014

[6] M. Mokhtari and Z. Abdul-Malek, "The Effect of Grounding Electrode Parameters on Soil Ionization and Transient Grounding Resistance using Electromagnetic Field Approach,” Applied Mechanics and Materials, vol. 554, pp. 628-632, 2014

[7] M. Mokhtari and Z. Abdul-Malek, "A Critical Review on Soil Ionisation Modelling for Grounding Electrodes," Archives of Electrical Engineering, forthcoming, vol/issue: 65(257), 2016.

[8] M. Mokhtari, et al., "Integration of Frequency Dependent Soil Electrical Properties in Grounding Electrode Circuit Model," International Journal of Electrical and Computer Engineering, vol/issue: 6(2), 2016.

[9] M. Mokhtari, et al., "The effect of soil ionization on transient grounding electrode resistance in non-homogeneous soil conditions," International Transactions on Electrical Energy Systems. Published online in Wiley Online Library, 2015. DOI: 10.1002/etep.2157.

[10] M. Mokhtari, et al., "An Improved Circuit-Based Model of a Grounding Electrode by Considering the Current Rate of Rise and Soil Ionization Factors," Power Delivery, IEEE Transactions on, vol/issue: 30(1), pp. 211-219, 2015.

[11] S. Lim, et al., "Behaviour Of Backfill Materials For Electrical Grounding Systems Under High Voltage Conditions," Journal of Engineering Science and Technology, vol/issue: 10(6), pp. 811-826, 2015

[12] H. M. Ismail, "Effect of oil pipelines existing in an HVTL corridor on the electric-field distribution," Power Delivery, IEEE Transactions on, vol/issue: 22(4), pp. 2466-2472, 2007. 
[13] N. M. Abdel-Gawad, et al., "Mitigation of induced voltages and AC corrosion effects on buried gas pipeline near to OHTL under normal and fault conditions," Electric Power Systems Research, vol. 127, pp. 297-306, 2015.

[14] F. Dawalibi and R. D. Southey, "Analysis of electrical interference from power lines to gas pipelines. II. Parametric analysis," Power Delivery, IEEE Transactions on, vol/issue: 5(1), pp. 415-421, 1990.

[15] I. Metwally and F. Heidler, "Mitigation of the produced voltages in AC overhead power-lines/pipelines parallelism during power frequency and lightning conditions," European transactions on electrical power, vol/issue: 15(4), pp. 351-369, 2005.

[16] I. Cotton, et al., "Comparison of transient and power frequency-induced voltages on a pipeline parallel to an overhead transmission line," Power Delivery, IEEE Transactions on, vol/issue: 22(3), pp. 1706-1714, 2007.

[17] K. Kopsidas and I. Cotton, "Induced voltages on long aerial and buried pipelines due to transmission line transients," Power Delivery, IEEE Transactions on, vol/issue: 23(3), pp. 1535-1543, 2008.

[18] G. C. Christoforidis, et al., "Induced voltages and currents on gas pipelines with imperfect coatings due to faults in a nearby transmission line," in Power Tech Proceedings, 2001 IEEE Porto, 2001.

[19] G. Christoforidis, et al., "Inductive interference calculation on imperfect coated pipelines due to nearby faulted parallel transmission lines," Electric Power Systems Research, vol/issue: 66(2), pp. 139-148, 2003.

\section{BIOGRAPHIES OF AUTHORS}

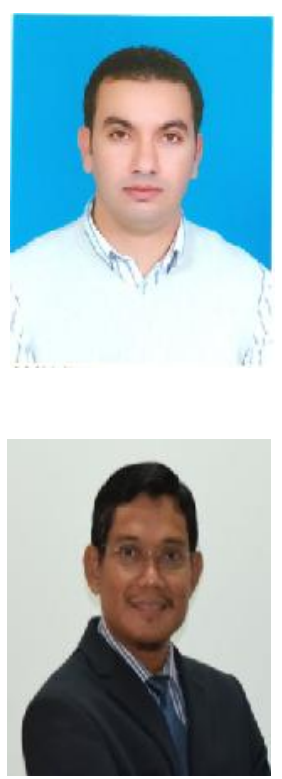

Ali I. El Gayar is a Lecturer and the Head of Control Department at College of Electrical and Electronics Technology-Benghazi-Libya. He is currently reading for his Ph.D. degree at Universiti Teknologi Malaysia. He obtained his Bachelor's degree in Electrical Engineering from Benghazi University, Libya,in 2005. He was the Field Engineer at Schlumberger from 2005 to 2006, and then moved to Halliburton as Logging Engineer from 2006 to 2009. He obatined his Masters degree in Electrical Engineering from UTHM, Malaysia, in 2011. His research interests are high voltage, transmission line, induced voltages, pipeline, corrosion, and lightning.

Zulkurnain Abdul-Malek received his B.E. in electrical and computer system from Monash University, Melbourne in 1989, M.Sc. in electrical and electromagnetic engineering with industrial applications from University of Wales Cardiff, United Kingdom in 1995 and subsequently obtained his Ph.D. in high voltage engineering from the same university in 1999. He has been a Lecturer with UTM for 25 years, where he is currently a Professor of high voltage engineering in the Faculty of Electrical Engineering. His research interests include high voltage instrumentation, lightning protection, detection and warning systems, partial discharges, nanodielectrics, and condition monitoring of power equipment. He is currently the Director of Institute of High Voltage and High Current, Universiti Teknologi Malaysia. He has published two books, and has authored and co-authored over 200 papers in various technical journals and conference proceedings. Abdul-Malek is actively involved in many committees including IEC TC 42 Maintenance Team 03 and Task Force for High Voltage Equipment, Committee of Testing Laboratories. He is the Chairman of Malaysian Working Group on High-Voltage Test Techniques and MyHVnet. He is also a member of Malaysia IECEE Certification Body Management Committee, Malaysia Technical Committee on High Voltage Power Transmission, and Malaysia Department of Standards IEC 17025 Technical Assessors. He is a member of IEEE (PES \& DEIS) and CIGRE. 